\title{
Arahan Mitigasi Bencana Kawasan Rawan Longsor di Kabupaten Sinjai
}

\author{
Directions for Disaster Mitigation of Landslide Prone Areas In Sinjai Regency \\ Muhammad Hanif Zahran', Agus Salim ${ }^{1,2,}$, Tri Budiharto ${ }^{1}$ \\ ${ }^{1}$ Program Studi Perencanaan Wilayah dan Kota, Fakultas Teknik, Universitas Bosowa \\ ${ }^{2}$ Program Studi Pascasarjana Perencanaan Wilayah dan Kota, Fakultas Teknik, Universitas Bosowa \\ Email: muhammadhanifzahran@gmail.com6
}

\section{Artikel info}

\section{Artikel history:}

Diterima; 09-03-2021

Direvisi: 25-03-2021

Disetujui; 31-03-2021

\author{
Keywords: \\ Disaster; Mitigasion; \\ Prone ; Landslide \\ Region Sinjai ;
}

\begin{abstract}
This study aims to identify areas prone to landslides in Sinjai Regency and propose directions for the use of landslide prone areas according to the level of landslide vulnerability in Sinjai Regency based on mitigation. This study uses quantitative research with analytical techniques used including basic physical conditions, vegetation, superimpose, and descriptive qualitative. The results showed that the distribution of landslide-prone areas in Sinjai Regency is located in West Sinjai, South Sinjai, and Sinjai Borong Districts. From the total area, South Sinjai is a sub-district whose area is dominant and has a high level of vulnerability. Directions for spatial use based on zone typology and the level of landslide vulnerability at the research location are proposed in the form of recommendations for regulating land use, as well as forms of mitigation in the form of general recommendations in accordance with the characteristics of landslide-prone areas.
\end{abstract}

\begin{abstract}
Abstrak. Penelitian ini bertujuan untuk mengindentifikasi dimana saja zona daerah rawan longsor di Kabupaten Sinjai dan mengusulkan arahan pemanfaatan ruang daerah rawan longsor menurut tingkat kerawanan longsor di Kabupaten Sinjai berbasis mitigasi. Penelitian ini menggunakan penelitian kuantitatif dengan teknik analisis yang digunakan diantaranya kondisi fisik dasar, vegetasi, superimpose, dan deskriptif kualitatif. Hasil penelitian dapat diketahui bahwa sebaran daerah rawan longsor di Kabupaten Sinjai terletak di Kecamatan Sinjai Barat, Sinjai Selatan, dan Sinjai Borong. Dimana dari total luas keseluruhan, Sinjai Selatan merupakan kecamatan yang luas wilayahnya dominan memiliki tingkat kerawanan tinggi. Arahan pemanfaatan ruang berdasarkan tipologi zona dan tingkat kerawanan longsor pada lokasi penelitian diusulkan berupa bentuk rekomendasi terhadap pengaturan penggunaan lahannya, serta bentuk mitigasinya berupa rekomendasi secara umum sesuai dengan karakteristik pada kawasan rawan bencana longsor.
\end{abstract}

Coresponden author:

Email: muhammadhanifzahran@gmail.com

artikel dengan akses terbuka dibawah lisensi CC BY -4.0

\section{PENDAHULUAN}

Berdasarkan Undang-Undang Republik Indonesia No. 24 Tahun 2007, tentang penanggulangan bencana menyatakan bahwa bencana merupakan suatu peristiwa yang tidak dapat di prediksi kejadiannya serta dapat mengancam dan mengganggu kehidupan masyarakat baik oleh faktor alam maupun faktor non alam.

Sesuai pada Peraturan Kepala Badan Nasional Penanggulangan Bencana No. 4 tahun 2008, menjelaskan bahwa faktor bencana alam yang sering terjadi di Indonesia meliputi, bencana akibat faktor alam dan non alam. Bencana dengan faktor alam yang sering terjadi diantaranya bencana akibat aktivitas geologi yaitu gempa bumi, tsunami, dan erupsi gunung berapi, dan bencana akibat hidrometeorologi yaitu banjir, kekeringan, dan angin topan dan tanah longsor 
Tanah longsor merupakan perpindahan material pembentuk lereng berupa batuan, bahan rombakan, tanah, atau material campuran yang bergerak ke bawah lereng (Somantri dkk., t.t.). Bencana Longsor menjadi salah satu dari sekian banyak bencana yang sering terjadi di Indonesia. Menurut Badan Nasional Penanggulangan Bencana terdapat 40,9 juta orang yang bermukim di daerah rawan longsor, dan juga terdapat kurang lebih 2.000 kasus longsor yang pernah terjadi di Indonesia pada tahun 2005 hingga 2014, yang dimana setiap tahunnya mengalami peningkatan kejadian bencana longsor. Menurut data Badan Nasional Penanggulangan Bencana dalam peta jumlah kejadian bencana tanah longsor di Indonesia, diketahui bahwa Provinsi Sulawesi Selatan memiliki daerah dengan jumlah kejadian tanah longsor lebih dari 65 kejadian sejak tahun 2015 sampai dengan tahun 2020. Topografi di Sulawesi Selatan umumnya bergunung, bergelombang berbukit-bukit dan dipicu dengan curah hujan tinggi lebih dari $3414 \mathrm{~mm} 3$ pertahun memungkinkan daerahnya berpotensi terhadap kejadian tanah longsor. Salah satu kabupaten di Sulawesi Selatan yang sangat rentan dengan bencana alam longsor adalah Kabupaten Sinjai.

Menurut Peraturan Daerah Kabupaten Sinjai No.28 tahun 2012 tentang Rencana Tata Ruang Wilayah Kabupaten Sinjai Tahun 2012-2032 bahwa terdapat beberapa titik rawan bencana longsor di Kabupaten Sinjai meliputi Kecamatan Sinjai Selatan, Sinjai Barat, Sinjai Tengah, Sinjai Borong, Tellulimpoe, dan Bulupoddo. Dari enam kecamatan tersebut yang paling parah terdapat di Kecamatan Sinjai Tengah, Sinjai Barat, dan Sinjai Borong hal ini dipicu dengan kondisi topografi mulai dari curam sampai sangat curam yang dikombinasikan dengan curah hujan yang tinggi, dimana curah hujan yang tinggi telah menyebabkan tanah longsor menimpa beberapa wilayah di Kabupaten Sinjai. Potensi bencana longsor yang terdapat di Kabupaten Sinjai pada umumnya terjadi pada wilayah dengan bentuk kemiringan lereng kisaran $>40 \%$ dengan kondisi vegetasi dan hutan yang sudah mengalami penggundulan yang disebabkan oleh pembukaan lahan perkebunan dan permukiman.

Kabupaten Sinjai memerlukan adanya arahan pemanfaatan ruang sebagai antisipasi adanya pembangunan di daerah rawan longsor, agar dampak bencana longsor bisa dikurangi. Geomorfologi Kabupaten Sinjai yang karakteristik fisik alaminya bervariasi, sangat membutuhkan sebuah kajian berupa identifikasi tipologi kawasan khususnya untuk kawasan bencana longsor. Sehingga menghasilkan informasi tingkat kerawanan bencana kawasan diwilayah tersebut, untuk dijadikan sebagai bahan masukan dan pertimbangan khususnya dalam penetapan rencana-rencana pemanfaatan penentuan pola ruang di Kabupaten Sinjai.

Maka dari itu penelitian ini penting karena akan menghasilkan tingkat kerawanan longsor yang diklasifikasikan kedalam beberapa tingkatan menurut tipologi zonanya. Kemudian juga akan menjelaskan secara deskriptif bagaimana arahan pemanfaatan ruangnya sesuai dengan tingkat kerawanannya.

Dengan adanya studi ini maka tujuan yang ingin dicapai yaitu: mengidentifikasi zona daerah rawan longsor di Kabupaten Sinjai menurut tingka kerawanannya, mengusulkan arahan pemanfaatan ruang daerah rawan longsor menurut tingklat kerawanan longsor di Kabupaten Sinjai berbasis mitigasi. Dengan harapan bahwa hasil dari penelitian ini dapat menjadi acuan dalam penaatan ruang di Kabupaten Sinjai.

\section{METODE}

\subsection{Jenis Penelitian}

Menurut Nazir 1988 metode penelitian merupakan suatu kesatuan sistem dalam penelitian yang terdiri dari prosedur dan teknik yang dilakukan pada suatu penelitian (Salim \& Ruslan, t.t.). Jenis penelitian yang digunakan dalam penelitian ini adalah penelitian kuantitatif. Penelitian ini bertujuan untuk memperoleh informasi potensi rawan bencana longsor yang terdapat di Kabupaten Sinjai dengan kuantitatif yaitu melalui perhitungan tabulatif. Penelitian kuantitatif merupakan jenis penelitian dengan menggunakan data-data tabulasi, data angka sebagai bahan pembanding serta bahan rujukan dalam menganalisis secara deskriptif.

\subsection{Lokasi dan Waktu Penelitian}

Penelitian ini dilaksanakan di Kabupaten Sinjai Propinsi Sulawesi Selatan. Secara geografis terletak antara

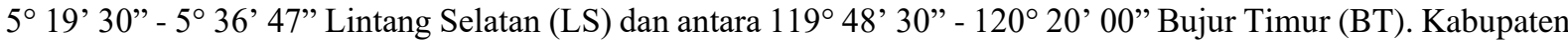
Sinjai mempunyai luas $819,96 \mathrm{~km}^{2}$. Dimana Kabupaten Sinjai merupakan salah satu kabupaten yang rawan akan terjadinya bencana longsor, sehingga peneliti memilih untuk melakukan penelitian di Kabupaten Sinjai untuk dapat mengetahui dimana saja zona yang rawan akan terjadinya longsor menurut tingkat kerawanannya.

Waktu penelitian berlangsung dari bulan Agustus. Dengan beberapa tahapan diantaranya observasi lapangan, kemudian pengambilan data di instansi, serta penyusunan laporan

\subsection{Jenis dan Sumber Data}

\subsubsection{Jenis Data}

Dalam penelitian ini, jenis data yang digunakan yaitu Data Kuantitatif, merupakan penelitian dengan memperoleh data yang berbentuk angka atau data kualitatif yang diangkakan data berbentuk numerik atau angka Sugiyono (dalam Burhanuddin, 2012) Data yang termasuk didalamnya yaitu data Kemiringan lereng, Curah hujan, 
Jenis tanah, Geologi/batuan, Tutupan lahan, Vegetasi.

\subsubsection{Sumber Data}

Kemudian untuk sumber data peneliti menggunakan sumber data primer dan sumber data sekunder:

\subsubsection{Data primer}

Data primer yaitu menurut Sugiyono (2009:137) data yang dibuat oleh peneliti untuk maksud khusus menyelesaikan permasalahan yang sedang ditanganninya (M dkk., 2020). Data dikumpulkan sendiri oleh peneliti langsung dari sumber pertama atau tempat objek penelituan ini dilakukan seperti data kependudukan, data kebencanaan, dan data citra satelit landsat 8 .

\subsubsection{Data sekunder}

Menurut Sugiyono (2009:137) yaitu data yang telah dikumpulkan untuk maksud selain menyelesaikan masalah yang sedang dihadapi, data ini dapat ditemukan dengan cepat (M dkk., 2020). Dalam penelitian ini yang menjadi sumber data sekunder berasal dari Badan Pusat Statistik Kabupaten Sinjai, Dinas Pekerjaan Umum dan Penataan Ruang Daerah Kabupaten Sinjai, Badan Perencanaan dan Pembnagujnan Daerah Kabupaten Sinjai, Badan Penelitian dan Pengembanagn Daerah Kkabupaten Sinjai, Badan Penanggulanan Bencana Kabupaten Sinjai, Dinas Lingkungan Hidup dan Kehutanan Kabupaten Sinjai, Dinas Kawasan Perumahan, Permukimnan dan Petanahan Kabupaten Sinjai, Kantor Kecamatan se-Kabupaten Sinjai.

\subsection{Populasi dan Sampel}

\subsubsection{Populasi}

Populasi adalah jumlah keseluruhan objek suatu penelitian yang memiliki ciri-ciri tertentu yang akan dikaji oleh peneliti. (Yunus,2010) mengatakan, populasi itu merupakan rangkaian satuan-satuan elementer yang mempunyai karakteristik dasar yang sama atau dianggap sama (Munandar, 2017). Populasi dalam penelitian ini adalah seluruh penduduk yang berada di Kabupaten Sinjai. Dalam penelitian ini jumlah populasi seluruh penduduk di Kabupaten Sinjai yang berjumlah 242.672 jiwa.

\subsubsection{Sampel}

Asnawi (2006:16) mengatakan sampel adalah pengambilan sebagian dari data populasi yang bertujuan dapat ditarik simpulan yang mereflesikannya (Hendria dkk., 2016). Adapun penelitian ini menggunakan rumus Slovin karena dalam penarikan sampel, jumlahnya harus representative agar hasil penelitian dapat digeneralisasikan dan perhitungannya pun tidak memerlukan tabel jumlah sampel, namun dapat dilakukan dengan rumus dan perhitungan sederhana.

Teknik Slovin menurut Sugiyono (2011:87) menetapkan rumus Slovin untuk menentukan sampel adalah sebagai berikut :

$n=\frac{N}{1+N(e)^{2}}$

Keterangan :

$\mathrm{n}=$ Ukuran sampel/jumlah responden

$\mathrm{N}=$ Ukuran populasi

$\mathrm{e}=$ Presentase error margin pengambilan sampel yang masih bisa ditolelir; $\mathrm{e}=0,1$

Dalam penelitian ini untuk tingkat kesalahan dalam penarikan sampel akan digunakan persentase sebesar $10 \%$, dan untuk lebih jelasnya mengenai jumlah sampel dalam penelitian ini adalah sebagai berikut:

$$
\begin{aligned}
& \mathrm{n}=\mathrm{N} /\left(1+\mathrm{N} \cdot(\mathrm{e})^{2}\right) \\
& \mathrm{n}=40.550 /\left(1+40.550 \cdot(0,1)^{2}\right) \\
& \mathrm{n}=40.550 / 405,51 \\
& \mathrm{n}=99,9
\end{aligned}
$$

Dari hasil perhitungan diatas dapat disimpulkan bahwa jumlah sampel yang akan digunakan dalam penelitian ini sebagai perwakilan dari keseluruhan populasi adalah sebanyak 100 jiwa penduduk.

\subsection{Variabel Penelitian}

Variabel dapat diartikan ciri dari individu objek, gejala, peristiwa yang dapat diukur secara kuantitatif ataupun kualitatif. Variabel dipakai dalam proses identifikasi, ditentukan berdasarkan kajian teori yang dipakai. Semakin sederhana suatu rancangan penelitian semakin sedikit variabel penelitian yang digunakan. Sugiyono, 2010 mengatakan secara teoritis variabel dapat didefinisikan sebagai atribut seseorang atau peneliti, atau objek yang mempunyai "variasi" antara satu dengan yang lain atau satu objek dengan objek yang lain (Muuzi dkk., t.t.). Adapun variabel yang digunakan dalam penelitian ini yaitu: 
- $\quad$ Kemiringan Lereng (X1)

- Curah Hujan (X2)

- Jemis Tanah (X3)

- $\quad$ Jenis Batuan $(\mathrm{X} 4)$

- $\quad$ Penggunaan Lahan (X5)

- $\quad$ Kerapatan Vegetasi (X6)

\subsection{Metode Analisis}

Metode analisis data yang digunakan dalam penelitian ini ada empat metode yaitu Analisis Kondisi Fisik Dasar, Analisis Vegetasi, Analisis Superimpose dan Analisis Deskriptif Kualitatif. Analisis ini digunakan sesuai dengan kebutuhan datanya. Untuk lebih jelasnya dapat dilihat pada tabel:

Tabel 1. Metode Penelitian

\begin{tabular}{|c|c|c|c|}
\hline No & Tujuan Penelitian & Variabel & Sumber Data dan Metode Analisis \\
\hline 1. & $\begin{array}{c}\text { Mengidentifikasi } \\
\text { zonasi daerah rawan } \\
\text { longsor }\end{array}$ & $\begin{array}{l}\text { 1. Kemiringan lereng } \\
\text { 2. Curah hujan } \\
\text { 3. Jenis Tanah } \\
\text { 4. Batuan } \\
\text { 5. Tutupan Lahan } \\
\text { 6. Vegetasi (KerapatanVegetasi) }\end{array}$ & $\begin{array}{l}\text { Data diperoleh melalui : } \\
\text { 1. Data Primer dengan observasi awal } \\
\text { pada setiap variabel } \\
\text { 2. Data Sekunder yang didapatkan dari } \\
\text { beberapa instansi terkait dan data } \\
\text { kebencanaan terkait longsor di } \\
\text { BPBD Kabupaten Sinjai } \\
\text { Analisis } \\
\text { 1. Analisis kondisi fisik dasar. } \\
\text { 2. Analisis Vegetasi (untuk mengetahui } \\
\text { kerapatan vegetasi) } \\
\text { 3. Analisis superimpose (untuk } \\
\text { menentukan zona daerah rawan } \\
\text { longsor menurut tipe zona dan } \\
\text { tingkat kerawanan). }\end{array}$ \\
\hline 2. & $\begin{array}{l}\text { Mengusulkan arahan } \\
\text { pemanfaatan ruang } \\
\text { daerah rawan longsor } \\
\text { berbasis mitigasi. }\end{array}$ & $\begin{array}{l}\text { 1. Tipologi zona A tingkat } \\
\text { kerawanan tinggi, sedang dan } \\
\text { rendah. } \\
\text { 2. Tipologi zona B tingkat } \\
\text { kerawanan tinggi, sedang dan } \\
\text { rendah. } \\
\text { 3. Tipologi zona C tingkat } \\
\text { kerawanan tinggi, sedang dan } \\
\text { rendah. }\end{array}$ & $\begin{array}{l}\text { Data diperoleh melalui } \\
\text { Data Primer hasil dari pengolahan data } \\
\text { pada rumusan masalah pertama } \\
\text { Analisis } \\
\text { Deskriptif kualitatif }\end{array}$ \\
\hline
\end{tabular}

\section{HASIL DAN PEMBAHASAN}

\subsection{Hasil}

\subsubsection{Gambaran Umum Lokasi Penelitian}

Secara geografis Kabupaten Sinjai terletak antara $5^{\circ} 2^{\prime} 56^{\prime \prime}$ sampai dengan $5^{\circ} 21^{\prime} 16^{\prime \prime}$ Lintang Selatan dan $119^{\circ} 56^{\prime} 30^{\prime \prime}$ sampai dengan $120^{\circ} 25^{\prime} 33^{\prime \prime}$ Bujur Timur. Kabupaten Sinjai merupakan salah satu dari 24 kabupaten atau kota dalam wilayah Provinsi Sulawesi Selatan yang terletak dipantai timur bagian selatan Sulawesi selatan berjarak kurang lebih $223 \mathrm{~km}$ dari kota Makassar (ibu kota Sulawesi Selatan). Secara keseluruhan luas wilayah Kabupaten Sinjai adalah $819,96 \mathrm{~km} 2$, yang secara administrasi terbagi menjadi 9 kecamatan yakni Kecamatan Bulupoddo, Kecamatan Pulau Sembilan Kecamatan Sinjai Barat, Kecamatan Sinjai Borong, Kecamatan Sinjai Selatan, Kecamatan Sinjai Tengah, Kecamatan Sinjai Timur, Kecamatan Sinjai Utara, dan Kecamatan Tellulimpoe. Serta terdiri dari 80 desa dan kelurahan. 


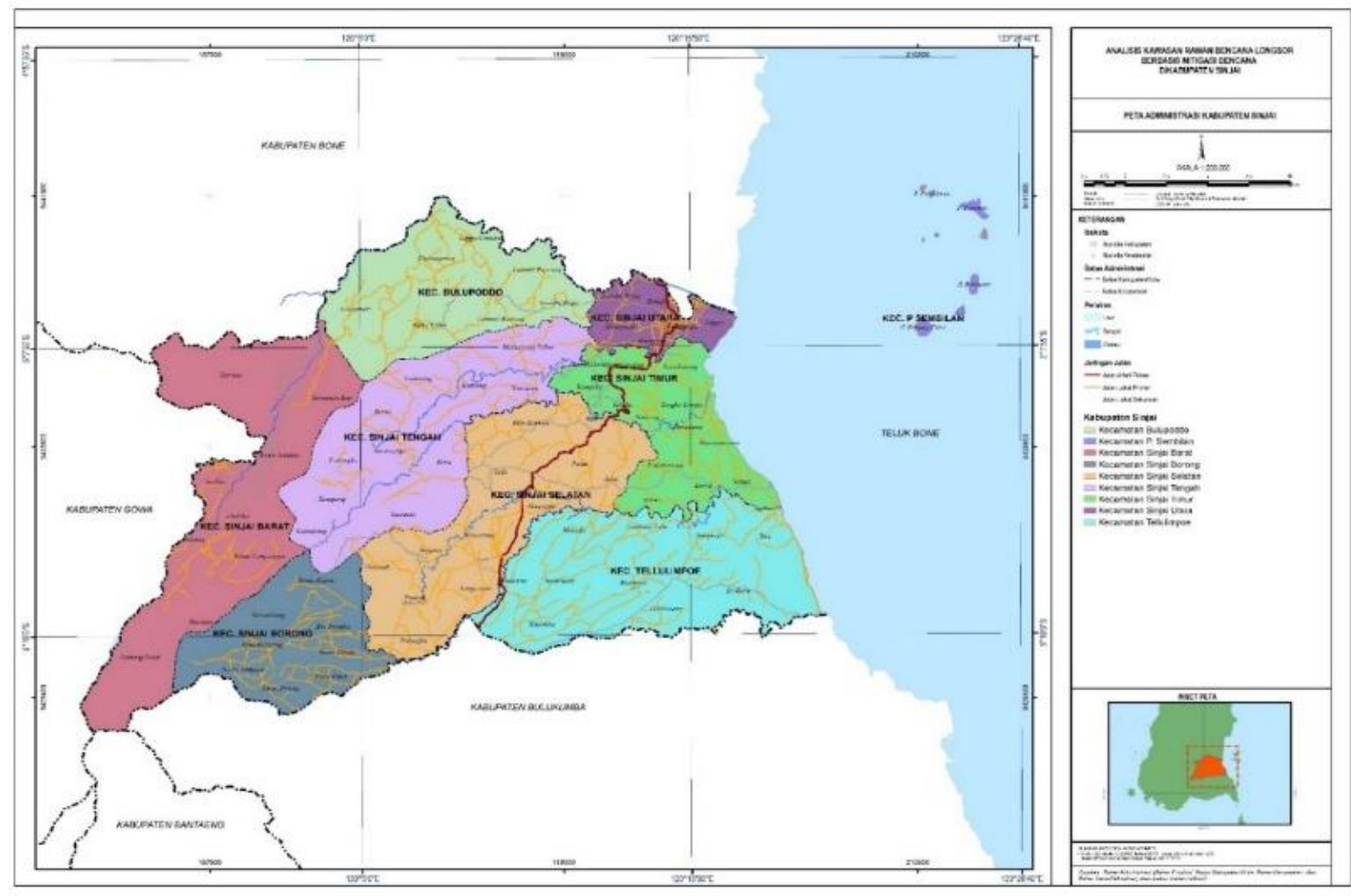

Gambar 1. Peta Administrasi Kabupaten Sinjai

\subsection{Historikal dan Karakteristik Bencana Longsor di Kabupaten Sinjai}

Berdasarkan datan Badan Penanggulangan Bencana Daerah Kabupaten Sinjai tahun 2015-2019 mengenai kejadian tanah longsor. Dan diketahui pada tahun tersebut telah terjadi lebih dari 20 kali kejadian tanah longsor di Kabupaten Sinjai. Dimana kejadian longsor tersebar hampir semua kecamatan seperti di Kecamatan Sinjai Barat, Sinjai Selatan, Sinjai Borong, Sinjai Tengah, Dan Bulupoddo.

Tabel 2. Data Kejadian Bencana Longsor Per-Kecamatan di Kabupaten Sinjai

\begin{tabular}{|c|c|c|c|c|c|c|}
\hline \multirow[t]{2}{*}{ No } & \multirow[t]{2}{*}{ Kecamatan } & \multicolumn{5}{|c|}{ Jumlah Kejadian/Tahun } \\
\hline & & 2019 & 2018 & 2017 & 2016 & 2015 \\
\hline 1 & Bulupoddo & 1 & - & 4 & 1 & - \\
\hline 2 & Pulau Sembilan & - & 4 & - & & - \\
\hline 3 & Sinjai Barat & 2 & 5 & 4 & - & - \\
\hline 4 & Sinjai Borong & 3 & 5 & - & - & - \\
\hline 5 & Sinjai Selatan & 4 & - & 18 & 2 & 1 \\
\hline 6 & Sinjai Tengah & 6 & 4 & 7 & 2 & \\
\hline 7 & Sinjai Timur & 7 & - & 8 & & 1 \\
\hline 8 & Sinjai Utara & 3 & - & - & - & 1 \\
\hline 9 & Tellu Limpoe & - & 2 & 1 & - & 1 \\
\hline
\end{tabular}

Sumber : Badan Penanggulangan Bencana Daerah Kabupaten Sinjai

\subsection{Pembahasan}

\subsubsection{Analisis Kondisi Fisik Dasar}

Analisis kondisi fisik dasar pada umumnya merupakan analisis untuk mengenali karakteristik pada suatu kawasan, yang dimana meliputi analisis kemiringan lereng, analisis curah hujan, analisis kondisi batuan dan analisis jenis tanah di Kabupaten Sinjai.

\subsubsection{Analisis Kondisi Kondisi Kemiringan Lereng}

Kondisi topografi di Kabupaten Sinjai bermacam-macam mulai dari datar, landai, bergelombang, hingga bergunung dengan kisaran ketinggian dari 0 hingga pada titik tertinggi melebihi 1000 meter di atas permukaan laut (mdpl) serta dengan kemiringan lereng mulai 0\% hingga melebihi dari 40\%, dengan kondisi tersebut maka 
berpotensi terhadap terjadinya longsor lahan, utamanya pada sepanjang wilayah utara, tengah hingga barat Kabupaten Sinjai.

\subsubsection{Analisis Kondisi curah Hujan}

Rata-rata kondisi curah hujan di Kabupaten Sinjai pertahunnya berada antara 1973mm hingga 3060mm, yang dimana curah hujan tertinggi terjadi pada bulan Februari - Juli. Namun pada tahun 2018 dengan kondisi curah hujan yang cukup tinggi yaitu 3060mm pertahun yang terjadi November - Juni, adapun wilayahnya meliputi: Kecamatan Tellulimpoe, Sinjai Selatan.

\subsubsection{Analisis Kondisi Geologi}

Dilihat dari kondisi fisik Kabupaten Sinjai jenis batuan yang mendominasi ialah batuan sedimen yang tersebar di utara hingga selatan Kabupaten Sinjai, sedang batuan beku hanya tersebar di bagian barat. Dari data tersebut diketahui bahwa bagian utara menuju ke selatan merupakan daerah yang rawan terjadinya longsor dilihat dari kondisi batuannya, jika dilihat pada peta Sinjai Selatan menjadi daerah yang perlu diwaspai sebab batuan sedimen mendominasi di daerah tersebut.

\subsubsection{Analisis Kondisi Tanah}

Berdasarkan data yang diperoleh jenis tanah yang terdapat di Kabupaten Sinjai antara lain Aluvial, Andosol, Gleisol, Kambisol, Mediteran, dan Podsolik. Jadi wilayah Kabupaten Sinjai yang perlu diwaspadai terhadap bencana longsor dengan dilihat jenis tanahnya terdapat di Kecamatan Sinjai Barat dan Sinjai Tengah

\subsubsection{Analisis Tutupan Lahan}

Penggunaan lahan di Kabupaten Sinjai sendiri didominasi oleh semak belukar, Hutan yang merupakan kawasan lindung hanya berada di Kecamatan Sinjai Borong dan Sinjai Barat, itupun dengan sebaran yang tidak merata. Seiring bertambahnya penduduk maka diperlukan pembukaan lahan oleh masyarakat untuk dijadikan permukiman dan perkebunan. Salah satu faktor paling penting terhadap terjadinya longsor yaitu kegiatan manusia yang cepat dan intensif. Dimana kebanyakan kegiatan berkaitan dengan perubahan faktor-faktor yang berpengaruh terhadap erosi, seperti pada kasus diatas yang dimana masyakat melakukan pembabatan hutan untuk lahan pertanian, perkebunan, hingga permukiman.

Daerah dengan kondisi seperti ini terdapat pada Kecamatan Sinjai Barat, dan Sinjai Borong yang dimana fungsi lindung kemudian diubah sebagai lahan perkebunan, ladang,dan permukiman apalagi daerah terletak pada kemiringan lebih $40 \%$ sehingga mempunyai pengaruh besar terhadap kejadian longsor.

\subsubsection{Analisis Vegetasi}

Kabupaten Sinjai berdasarkan kerapatan vegetasi yang dibagi menjadi menjadi lima klasifikasi yakni lahan tidak bervegetasi, kehijauan sangat rendah, kehijauan rendah, kehijauan sedang, kehijauan tinggi. Di Kabupaten Sinjai untuk daerah yang memiliki tingkat kerapatan atau tidak memiliki vegetasi terdapat di Kecamatan Sinjai Utara. Hal ini disebabkan karena Kecamatan Sinjai Utara merupakan pusat kota di Kabupaten Sinjai sehingga kerapatan vegetasipun terbilang tidak ada. Hal ini bisa saja mempengaruhi akan terjadinya longsor tapi dengan melihat kondisi fisik lainnya juga. Dan untuk tingkat kerapatan vegetasi tinggi masih terdapat pada di hampir seluruh wilayah Kecamatan Sinjai Tengah

\subsubsection{Analisis Superimpose}

Untuk mendapatkan tingkat kerawanan longsor di Kabupaten Sinjai maka diperlukan proses overlay. Dari hasil overlay, nantinya akan menghasilkan tiga tingkat kerawanan yaitu, tingkat kerawan rendah, tingkat kerawan sedang, dan tingkat kerawanan tinggi. Berdasarkan hasil yang diperoleh diketahui bahwa Kabupaten Sinjai daerahnya ini tidak rentang terhadap kejadian longsor dan dapat dilihat pada tabel berikut;

Tabel 3. Luasan Tingkat Kerawanan Longsor Per-Kecamatan di Kabupaten Sinjai

\begin{tabular}{lrrrr}
\hline \multirow{2}{*}{ Kecamatan } & \multicolumn{3}{c}{ Tingkat Kerawanan } & Total \\
\cline { 2 - 5 } & \multicolumn{2}{c}{ Tinggi (Ha) } & Sedang (Ha) & Rendah (Ha) \\
\hline Bulupoddo & - & $8.654,04$ & $1.657,03$ & $10.311,07$ \\
P. Sembilan & - & 94,06 & 81,94 & 176,00 \\
Sinjai Barat & 119,83 & $15.255,23$ & 224,27 & $15.599,33$ \\
Sinjai Borong & 75,96 & $7.932,71$ & 19,54 & $8.028,21$ \\
Sinjai Selatan & 245,90 & $12.614,95$ & 459,05 & $13.319,90$ \\
Sinjai Tengah & 11,23 & $13.184,03$ & 776,18 & $13.971,44$ \\
Sinjai Timur & 2,99 & $6.406,83$ & 1250,99 & $7.660,81$ \\
Sinjai Utara & 3,41 & $1.369,49$ & 1433,42 & $2.806,32$ \\
Tellulimpoe & 12,22 & $9.947,00$ & 163,23 & $10.122,45$ \\
\hline Total & 471,54 & $75.458,34$ & $6.065,65$ & 81.996 \\
\hline Persentase & $0,57 \%$ & $92,02 \%$ & $7,39 \%$ & $100 \%$ \\
\hline
\end{tabular}




\subsubsection{Analisis Arahan Pemanfaatan Ruang kabupaten Sinjai Berbasis Mitigasi Bencana}

Arahan pemanfaatan ruang berbasis mitigasi bencana longsor merupakan bentuk penataan ruang wilayah dengan mengutamakan pertimbangan pada kondisi fisik dasar wilayah tersebut. Arahan pemanfaatan ruang berbasis mitigasi menekankan agar setiap daerah mampu mengarahkan daerahnya dengan konsep pemanfaatan ruang yang berbasis mitigasi bencana terutama pada daerah yang dari segi letak geografisnya merupakan daerah yang rawan akan terjadinya longsor.

Zona dengan tingkat kerawanan sedang merupakan zona yang agak atau tidak begitu rawan terhadap longsor. Penggunaan ruang pada zona berpotensi longsor dengan tingkat kerawanan sedang tidak layak untuk kegiatan industri (pabrik) hal ini disebabkan karena getaran dapat memicu terjadinya suatu longsor, namun untuk kegiatan lain dapat dilakukan dengan persyaratan yang ketat diantaranya,1) Industri/pabrik, tidak layak dibangun, 2) Kegiatan hunian terbatas, dengan persyaratan sebagai berikut, Perlu dilakukan penyelidikan geologi teknik, analisis kestabilan lereng, serta daya dukung tanah, tidak mengganggu kestabilan lereng dan lingkungan, perlu diterapkan sistem drainase yang tepat pada lereng, sehingga dapat meminimalkan penjenuhan pada lereng, meminimalkan pembebanan pada lereng, melalui penetapan jenis bangunan dan kegiatan yang dilakukan, perlu diterapkan sistem perkuatan lereng untuk menambah gaya penahan gerakan tanah pada lereng, memperkecil kemiringan lereng, jalan direncanakan dengan mengikuti pola kontur lereng, dan mengosongkan lereng dari kegiatan manusia. 3) Kegiatan-kegiatan pertanian, perkebunan , hutan kota, hutan produksi, dapat dilaksanakan dengan beberapa persyaratan berikut, penanaman vegetasi dengan jenis dan pola tanam yang tepat, perlu diterapkan sistem terasering dan drainase yang tepat pada lereng, mengindari pemotongan dan penggalian lereng.

\subsubsection{Bentuk Mitigasi Daerah Rawan Bencana longsor Menurut Karakteristik Kawasan}

Terdapat 2 bentuk mitigasi pada daerah atau kawasan yang rawan terhadap longsor seperti mitigasi struktural dan non struktural, yang dimana setiap tingkat kerawanan bencana longsor masing-masing berbeda bentuk mitigasinya. Menurut karakteristik kawasan di Kabupaten Sinjai, daerah rawan longsor terjadi pada daerah tekuk lereng (daerah peralihan terjal dan datar), dan pada lereng tebing sungai. Untuk mitigasinya membutuhkan kajian sangat dalam, namun secara sederhana bentuk rekomendasi penanganannya dapat dilakukan dengan beberapa metode yang memfokuskan pada daerah-daerah tersebut.

\subsubsection{Mitigasi Struktural}

Adapun bentuk mitigasi structural meliputi daerah tekuk lereng dan daerah aliran sungai, dan dibagi kedalam masingmasing 2 bentuk rekomendasi mitigasi yaitu : metode vegetative meliputi daerah yang mengalami pengunduan hutan dapat diupayakan untuk ditanami dengan jenis tamanan budidaya yang bermanfaat bagi masyarakat. dan metode teknik sipil meliputi : pembentukan ereng lahan menjadi lebih landai pada daerah yang berpotensi rawan longsor, penguatan lereng terjal dengan bangunan penahan longsor pada kaki lereng berupa Angker, Bronjongm dinding penahan srta menerapkan sistem drainase yang tepat pada lereng rawan longsor.

Kemudian yang kedua yaitu daerah aliran sungai, dengan cara metode vegetative yaitu Kawasan dengan tingkat kerawanan tinggi dan mengalami penggundulan dapat diupayakan untuk ditanami kembali, dengan jenis tanaman berupa semak yang mengikat kuat pada lereng sungai., Jenis tanaman sebaiknya memiliki sifat perakaran dalam, perakaran rapat dan mengikat agregat tanah, dan disarankan untuk tidak dipilih jenis tanaman yang tidak terlalu berat (bobot biomassanya ringan) dan berakar tunggang, Jenis tanaman yang disarankan untuk dapat menguatkan tanah pada lereng diantaranya adalah bambu. dan adapun bntuk mitigasi metode teknik sipilny yaitu meliputi: Pembentukan lereng lahan menjadi landai pada daerah yang berpotensial terjadi longsor (Slope Reshaping), Mengurangi pembebanan pada lereng, dan sebaiknya menghindari pembangunan pada daerah tebing sungai, Penguatan lereng terjal dengan bangunan penahan longsor pada lereng tebing sungai dapat dilakukan dengan kontruksi Bronjong dan Rip-Rap.

\subsubsection{Mitigasi Non Struktural}

Meliputi 3 susunan yaitu tinggi, sedang, rendah. Yaitu berupa: Early Warning System, Menyusun Rencana Kontijensi, Penyediaan informasi bencana longsor, Sosialisasi, Penguatan Ketahanan Masyarakat, Program Edukasi.

\section{KESIMPULAN}

Kesimpulan dalam penelitian akan menjawab rumusan masalah yang terdapat dalam penelitian ini. Berikut kesimpulan untuk dua rumusan masalah sebagai berikut: 1) Dapat disimpukan untuk rumusan masalah pertama yang dijawab menggunakan metode Analisis Superimpose, dapat diketahui bahwa sebaran daerah rawan longsor di daerah Kabupaten Sinjai terletak di Kecamatan Sinjai Barat, Sinjai Selatan dan Sinjai Borong. Dimana dari total keseluruhan, Sinjai Selatan merupakan kecamatan yang luas wilayahnya dominan memiliki tingkat kerawanan tinggi. 2) Untuk arahan pemanfaatan ruang berdasarkan tipologi zona dan tingkat kerawanan longsor pada lokasi peneitian diusulkan berupa bentuk rekomendasi terhadap pengaturan penggunaan lahannya. Dan bentuk mitigasinya berupa rekomendasi secara umum sesuai dengan karakteristik pada kawasan rawan bencana longsor.

Kemudian dari hasil Penelitian ini, maka terdapat beberapa saran yang meliputi: 1) Diharapkan hasil dari penelitian bisa menjadi bahan pertimbangan dari pemerintah agar mampu menerapkan hasil'rencana dan memberikan infomasi terkait daerah rawan longsor di'lokasi penelitian terkait bentuk arahan'pemanfaatan ruang 
di daerah rawan longsor. 2) Masukan bagi peneliti selanjutnya, karena penelitian ini masih jauh dari kesan sempurna, karena dalam penelitian ini banyak variabel yang tidak dikaji.

\section{DAFTAR PUSTAKA}

Burhanuddin, A. (2013, Mei 21). Penelitian Kuantitatif Dan Kualitatif. Afid Burhanuddin. Https://Afidburhanuddin.Wordpress.Com/2013/05/21/Penelitian-Kuantitatif-Dan-Kualitatif/

Hendria, R., Ahman, E., \& Novalita, D. P. (2016). Pengaruh Program Direct Marketing Terhadap Keputusan Menggunakan Meeting Package Grand Hotel Lembang (Survei Pada Tamu Bisnis Di Grand Hotel Lembang). The Journal: Tourism And Hospitality Essentials Journal, 4(1), 705. Https://Doi.Org/10.17509/Thej.V4i1.1979

M, M., Rafi, M., \& Muthia, M. (2020). Evaluasi Perda Kota Palu Nomor 6 Tahun 2012 Tentang Penertiban Ternak. Journal Of Public Administration And Government, 2(2), 60-64. Https://Doi.Org/10.22487/Jpag.V2i2.109

Munandar, B. (2017). Demografi Dan Kependudukan. 2(1), 10.

Muuzi, M., Surya, B., \& Aksa, K. (T.T.). Journal Of Urban Planning Studies. 01(01), 20.

Perda No. 28 Th 2012 Rtrw Kab. Sinjai.Pdf. (T.T.). Diambil 9 Februari 2021, Dari Https://Jdih.Sinjaikab.Go.Id/Jdih/Jdih/Dokumen/Perda\%20no.\%2028\%20th\%202012\%20rtrw\%20kab.\%20 sinjai.Pdf

Perka Bnpb 4-2008_Pedoman Penyusunan Rencana Penanggulangan Bencana.Pdf. (T.T.). Google Docs. Diambil 9 Februari 2021, Dari Https://Drive.Google.Com/File/D/0bxb8ijwcudeulvo0ttrxagduvml4bi1nmfqty0iyuq/View?

Salim, A., \& Ruslan, R. (T.T.). Journal of Urban Planning Studies. 01(01), 12.

Somantri, L., Pd, S., \& Si, M. (T.T.). Kajian Mitigasi Bencana Longsor Lahan. 10.

Uu No. 24 Tahun 2007 Tentang Penanggulangan Bencana [Jdih Bpk Ri]. (T.T.). Diambil 9 Februari 2021, Dari Https://Peraturan.Bpk.Go.Id/Home/Details/39901/Uu-No-24-Tahun-2007 